\title{
IVESTIGATION OF THE PROCESS OF TARTARIC ACID SEPARATION ON AMBERLITE XAD2 IMPREGNATED WITH AMBERLITE LA-2"
}

\author{
Natalia S. Marchitan \\ Department of Industrial and Ecological Chemistry, Faculty of Chemistry and Chemical Technology, \\ Moldova State University, 60 A. Mateevici str., MD 2009, Chisinau, Republic of Moldova \\ e-mail:n_marchitan@yahoo.com,te/faxl: +37322737165
}

\begin{abstract}
Tartaric acid is one of the most valuable compounds that can be obtained from secondary wine products. The last are accumulating in big quantities at winemaking factories from Moldova. This work describes an investigation of the process of reactive ion-exchange separation of tartaric acid from model systems with macroreticular resin Amberlite XAD2 impregnated with liquid ion-exchanger Amberlite LA-2 in batch equipment. The condition of Amberlite XAD2 impregnation process was investigated. Freudlich and Langmuir equations were verified and values of enthalpy, entropy and Gibbs energy were calculated.
\end{abstract}

Key words: reactive sorption, tartaric acid, Freudlich equation, Langmuir equation, thermodynamic constants.

\section{Introduction}

Classical technologies of organic compounds separation from aqueous streams possess several difficulties, which can be solved by application of reactive sorption. This procedure is a combination of reactive extraction and adsorption [1-5]. Impregnated ion-exchangers are obtained by physical incorporation of a selective extraction reagent into a porous adsorbent. The impregnated extractants manifest strong affinity towards polymeric resins, but, also, maintain its extractive properties (capacity and selectivity) as in liquid state [6-8]. The separation of the polar organic substance is performed during the contact between aqueous solution and impregnated ionites. It is obtained the complex between the solute and extractant. The reaction takes place in the pores of the resin, where the products remain [1-5]. In comparison to the reactive extraction, this procedure involves simpler technological equipment and operations, allows reduction of the total process time, does not need intensive agitation for increase the contact surface, avoids the emulsion formation, and can be used in case of small concentrations of the solute. Moreover, it is overcame basic disadvantage - low selectivity [5].

Impregnated resins with selective extractants were initially used for the separation of the metals from waste waters $[2,7,9-10]$. Later, this procedure was applied in water purification from organic compounds, and, finally, for their separation from other aqueous solutions [5,11-14]. Besides, studies of organic acids recovery are of strong interest $[3,4,15-17]$.

This work presents the study of the impregnation procedure of nonionic macroreticular resin Amberlite XAD2 with the solution of the secondary amine Amberlite LA-2 in organic solvent, and thermodynamic study of the reactive sorption of the tartaric acid on the obtained impregnated anionite.

\section{Experimental Section \\ Materials}

The aqueous phase was prepared by dissolving tartaric acid (Reahim, Russia) in distilled water. Several solvents were used as inert diluents for amine organic phase - chloroform, butyl acetate, hexane (all from Reahim, Russia). The organic phase for impregnation was prepared by dissolving amine: Amberlite LA-2, tri-n-octylamine, tri-iso-octylamine (Sigma-Aldrich, Germany) and synthesized amines (N-(2,2,4,4,6,6-hexamethylhexanyl)-N-(1methylenpirazyl)dodecylamine, $\quad \mathrm{N}-(2,2,4,4,6,6$-hexamethylhexanyl)-N-(1-methylen-1,2,4-triazyl)dodecylamine, $\mathrm{N}-(2,2,4,4,6,6$-hexamethylhexanyl)-N-(4-methylenmorpholyl)dodecylamine, $\quad \mathrm{N}-(2,2,4,4,6,6$-hexamethylhexanyl)$\mathrm{N}$-(1-methylenpyrrolidyl)dodecylamine, $\quad \mathrm{N}$-(N,N-diethylamino-N-methylen)-N-(2,2,4,4,6,6-hexamethylhexanyl) dodecylamine, N-(2,2,4,4,6,6-hexamethylhexanyl)-N-(1-methylenpyridyl)-dodecylamine, N-(N,N-dimethylamino$\mathrm{N}$-methylen)-N-(2,2,4,4,6,6-hexamethylhexanyl)dodecylamine, N,N,N-tri-iso-octylamine chloride, N-hydroxyethyl$\mathrm{N}, \mathrm{N}, \mathrm{N}$-trioctylammonium chloride and $\mathrm{N}, \mathrm{N}, \mathrm{N}, \mathrm{N}$-tetramethylheptylammonium bromide) in diluent. The synthesized tertiary amine and ammonium salts were obtained from commercial ones in laboratory of Organic Synthesize of Institute of Chemistry of ASM. Glacial acetic acid (Reactivul, Romania) and sodium metavadanate (Reahim, Russia) were used for determination of tartaric acid concentration.

\section{Methods}

Concentration determination of tartaric acid was realized by photometric method on spectrophotometer PD303 (APEL, Japan). For measurements $5 \mathrm{~cm}^{3}$ of analyzed solution were passed into $50 \mathrm{~cm}^{3}$ flask, $4 \mathrm{~cm}^{3}$ of sodium

\footnotetext{
" This article is an extended abstract of a communication presented at the Conference Ecological Chemistry 2012
} 
metavanadate solution (5\%) and $1 \mathrm{~cm}^{3}$ of glacial acetic acid were added, then flask was fitted with distilled water. Obtained solution is left for 15-20 min at dark for the formation of the stable color during $24 \mathrm{~h}$. Measurements were done at $525 \mathrm{~nm}$ wave length (green filter) against a blank similarly prepared without tested solution [18].

\section{Procedure}

The experimental procedure of the impregnation of the Amberlite XAD2 with Amberlite LA-2 consists of several stages. Initially, solid anionite is washed with acetone and distilled water to eliminate organic and inorganic impurities. Liquid amines are used without additional purification. Impregnation consists in immersion of the solid resin in solution of the liquid anionite in organic solvent. After $24 \mathrm{~h}$, necessary to fulfill impregnation process, the excess of the organic substance is removed by addition of the distilled water to the obtained anionite and its exposition to the ultrasound with the frequency $35 \mathrm{kHz}$ in ultrasound bath Sonica $1200 \mathrm{M}$ (Soltec, Italy) during $5 \mathrm{~min}$. Another possibility is to pour out remained amine solution by washing of the impregnated anionite with the same solvent, used for the preparation of the amine solution. Anionites obtained by both methods do not differ by their properties. For further experiments dry ionexchanger was used.

Determination of the reactive sorption performance of tartaric acid from model solution on obtained impregnated anionite was done as follows: $1 \mathrm{~g}$ of impregnated anionite is stirred with universal stirrer WU-4 (Premed, Poland) or agitator AVU-6s (Russia) with $50 \mathrm{~cm}^{3}$ of tartaric acid solution till the equilibrium is reached, and concentration of the tartaric acid is determined in the final solution [18].

Conditions of the impregnation process were determined from investigation of the next parameters: type of the amine (Amberlite LA-2, tri-n-octylamine, tri-iso-octylamine and synthesized amines), type of the solvent (hexane, chloroform, butylacetate), amine concentration in the impregnation solution, the volume of the solvent used in preparation of the impregnation solution and the time of impregnation. The impregnation performance was appreciated by determination of reactive sorption of the tartaric acid from model solution on impregnated anionite.

In order to estimate equilibrium constants for the reactive sorption process of the tartaric acid on anionite Amberlite XAD2 impregnated with Amberlite LA-2, $0.5 \mathrm{~g}$ of the anionite were stirred with $50 \mathrm{~cm}^{3}$ of tartaric acid solution with the concentration between $0.33 \mathrm{~g} / \mathrm{dm}^{3}$ and $6.99 \mathrm{~g} / \mathrm{dm}^{3}$, with the magnetic stirrer for an hour (time enough to create equilibrium state). The contact between the phases was ensured in thermostat during the whole process till the equilibrium state. In this way there were estimated the isotherms of the sorption at $296 \mathrm{~K}, 300 \mathrm{~K}, 305 \mathrm{~K}$ and $313 \mathrm{~K}$.

\section{Definition of Characteristic Parameters}

Reactive sorption at equilibrium $q_{e}(\mathrm{~g} / \mathrm{g})$ of the impregnated anionite is calculated by the formula:

$$
q_{e}=\frac{\left(c_{o}-c_{e}\right) \cdot V}{m},
$$

where: $m$ - mass of the dry ion-exchanger, g; $V$ - tartaric acid solution volume, $\mathrm{dm}^{3} ; c_{o}$ - initial concentration of the tartaric acid in model solution, $\mathrm{g} / \mathrm{dm}^{3} ; c_{e}-$ concentration of the tartaric acid in model solution at equilibrium, $\mathrm{g} / \mathrm{dm}^{3}$.

The constants of equilibrium were determined applying Freundlich and Langmuir equations.

For the determination of the constants $K_{F}$ and $n$, the data were used the Freundlich isotherm in logarithmic form:

$$
\ln q_{e}=\ln K_{F}+\frac{1}{n} \ln c_{e}
$$

where: $K_{F}-$ Freundlich equilibrium constant; $n$ - empiric parameter of heterogeneity of the surface [19-24].

The reverse of the Langmuir equation takes linear dependency:

$$
\frac{c_{e}}{q_{e}}=\frac{c_{e}}{q_{m}}+\frac{1}{q_{m} \cdot K_{L}}
$$

where: $\mathrm{K}_{\mathrm{L}}$ - Langmuir constant; $\mathrm{q}_{\mathrm{m}}$ - maximal specific adsorption ( $\left.\mathrm{mg} / \mathrm{g}\right)$, correspondent to the space occupied by a monomolecular layer on the adsorbent surface [19-25].

The precision of the correlation was appreciated by correlation coefficient $\mathrm{R}^{2}$ : 


$$
R_{y x}^{2}=r_{y x^{2}}^{2}=\frac{\left(\sum_{i}\left(y_{i}-\bar{y}\right)\left(x_{i}-\bar{x}\right)\right)^{2}}{\sum_{i}\left(y_{i}-\bar{y}\right)^{2} \sum_{i}\left(x_{i}-\bar{x}\right)^{2}}
$$

For the determination of the entropy and enthalpy through the graphic method was applied next form of the Van't Hoff equation:

$$
\ln K_{L}=-\frac{\Delta H^{o}}{R T}+\frac{\Delta S^{o}}{R}
$$

where: $\Delta H^{\circ}$ - enthalpy, $\mathrm{J} / \mathrm{mol} ; \Delta S^{o}$ - entropy, $\mathrm{J} /(\mathrm{mol} \cdot \mathrm{K}) ; R$ - universal constant of the ideal gas $(8,314 \mathrm{~J} /(\mathrm{mol} \cdot \mathrm{K}))$, and $T$ - temperature of the process realization $[24,26,27]$.

\section{Results and discussion}

The first stage of the determination of the conditions of impregnation process was amine selection. For this, there were prepared several impregnation solutions by dissolving $0.8 \mathrm{~cm}^{3}$ of amine in $3 \mathrm{~cm}^{3}$ of hexane. Next amines were used: Amberlite LA-2, tri-n-octylamine, tri-iso-octylamine, N-(2,2,4,4,6,6-hexamethylhexanyl)-N(1-methylenpirazyl)dodecylamine, $\quad \mathrm{N}-(2,2,4,4,6,6$-hexamethylhexanyl)-N-(1-methylen-1,2,4-triazyl)dodecylamine, $\mathrm{N}-(2,2,4,4,6,6$-hexamethylhexanyl)-N-(4-methylenmorpholyl)dodecylamine, $\quad \mathrm{N}-(2,2,4,4,6,6$-hexamethylhexanyl)$\mathrm{N}$-(1-methylenpyrrolidyl)dodecylamine, $\quad \mathrm{N}$-(N,N-diethylamino-N-methylen)-N-(2,2,4,4,6,6-hexamethylhexanyl) dodecylamine, N-(2,2,4,4,6,6-hexamethylhexanyl)-N-(1-methylenpyridyl)dodecylamine, N-(N,N-dimethylamino-Nmethylen)-N-(2,2,4,4,6,6-hexamethylhexanyl)dodecylamine, N,N,N-tri-iso-octylamine chloride, N-hydroxyethyl-N,N,Ntrioctylammonium chloride and N,N,N,N-tetramethylheptylammonium bromide. One gram of Amberlite XAD2 were added to the amine solution, stirred and left for $24 \mathrm{~h}$.

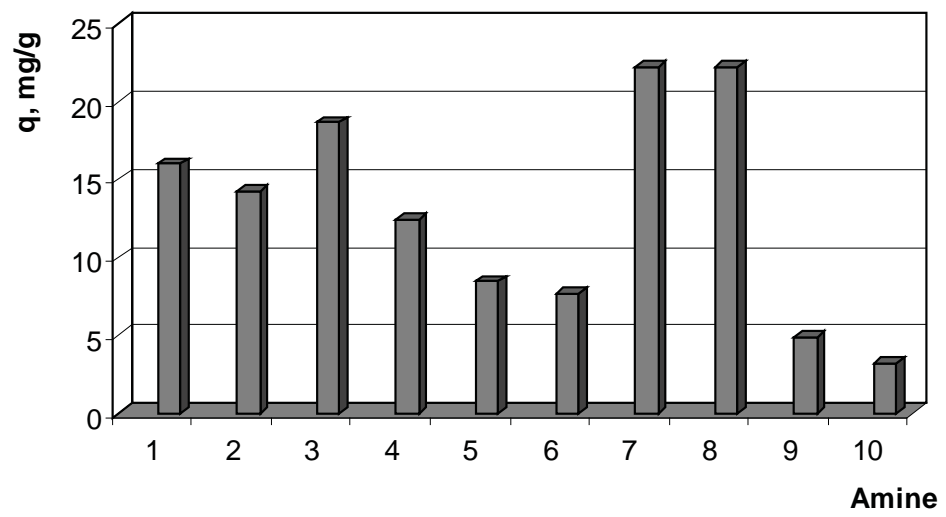

Fig. 1. The effect of the nature of the amine used for the impregnation of Amberlite XAD2 on reactive sorption of the tartaric acid from aqueous solution

$\left(\mathrm{m}(\right.$ anionite $\left.)=0.4 \mathrm{~g} ; \mathrm{d}_{\mathrm{p}}=0.75 \mathrm{~mm} ; \mathrm{V}(\mathrm{AT})=40 \mathrm{~cm}^{3} ; \mathrm{c}_{\mathrm{o}}(\mathrm{AT})=3.46 \mathrm{~g} / \mathrm{dm}^{3} ; \tau_{\text {agit }}=60 \mathrm{~min} ; \mathrm{t}=23^{\circ} \mathrm{C} ; \mathrm{n}=200 \mathrm{~min}^{-1}\right)$

1 - N-(2,2,4,4,6,6-hexamethylhexanyl)-N-(1-methylenpirazyl)dodecylamine, 2 - N-(2,2,4,4,6,6-hexamethylhexanyl)-N-

(1-methylen-1,2,4-triazyl) dodecylamine, 3 - N-(2,2,4,4,6,6-hexamethylhexanyl)-N-(4-methylenmorpholyl)dodecylamine,

4 - N-(2,2,4,4,6,6-hexamethylhexanyl)-N-(1-methylenpyrrolidyl) dodecylamine, 5 - N-(N,N-diethylamino-N-methylen)-N(2,2,4,4,6,6-hexamethylhexanyl) dodecylamine, 6 - N-(2,2,4,4,6,6-hexamethylhexanyl)-N-(1-methylenpyridyl) dodecylamine, 7 - N-(N,N-dimethylamino-N-methylen)-N-(2,2,4,4,6,6-hexamethylhexanyl)dodecylamine, 8 - N-(2,2,4,4,6,6-hexamethylhexanyl) dodecylamine (Amberlite LA-2), 9 - N,N,N-tri-iso-octylamine chloride, 10 - N-hydroxyethyl-N,N,N-trioctylammonium chloride

Tests of the obtained anionites revealed that maximal performance of reactive sorption of the tartaric acid was received for anionites impregnated with Amberlite LA-2 and (N,N-dimethylamino-N-methylen)-N-(2,2,4,4,6,6hexamethylhexanyl)dodecylamine. During separation with anionites impregnated with tri-n-octylamine, tri-isooctylamine, and N,N,N,N-tetramethylheptylammonium bromide was detected formation of the emulsion during stirring, caused by transfer of the amines from resin to aqueous solution, so they were excluded from following investigations. Thus, it was proposed to use Amberlite LA-2 amine for the impregnation of Amberlite XAD2, because the synthesis of (N,N-dimethylamino-N-methylen)-N-(2,2,4,4,6,6-hexamethylhexanyl)dodecylamine involves extra expenses, though process performance was unchangeable. 


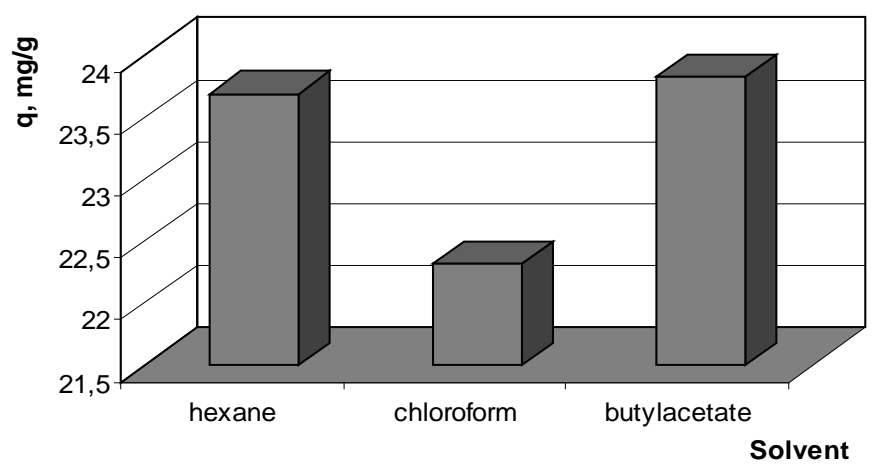

Fig. 2. The effect of amine solution solvent on reactive sorption of the tartaric acid from aqueous solution $\left(\mathrm{m}(\right.$ anionite $\left.)=1.0 \mathrm{~g} ; \mathrm{d}_{\mathrm{p}}=0.75 \mathrm{~mm} ; \mathrm{V}(\mathrm{AT})=50 \mathrm{~cm}^{3} ; \mathrm{c}_{\mathrm{o}}(\mathrm{AT})=3.48 \mathrm{~g} / \mathrm{dm}^{3} ; \tau_{\text {agit }}=60 \mathrm{~min} ; \mathrm{t}=28^{\circ} \mathrm{C} ; \mathrm{n}=200 \mathrm{~min}^{-1}\right)$

As solvents for impregnation were used: butylacetate, chloroform and hexane. According to the figure 2, amine solution preparation using butylacetate allows obtaining of the impregnated anionite with maximal sorption. Efficiency of the tartaric acid separation process with ion-exchanger prepared on basis of Amberlite LA-2 solution in chloroform was lower than in the case of other solvents. In addition, the separation process of the excess of impregnation solution becomes difficult, because chloroform has a higher density than water. Thus, hexane was used as solvent in the next experiments because the impregnated resins obtained from amine solution in hexane and from solution in butylacetate had nearly similar reactive sorption, but the separation of hexane was easier and faster, due to low boiling point $\left(69^{\circ} \mathrm{C}\right)$.

Amine concentration in impregnation solution varied from 5\% to $60 \%$. After, processing and testing of the impregnated anionite, there were obtained the results, presented in figure 3.

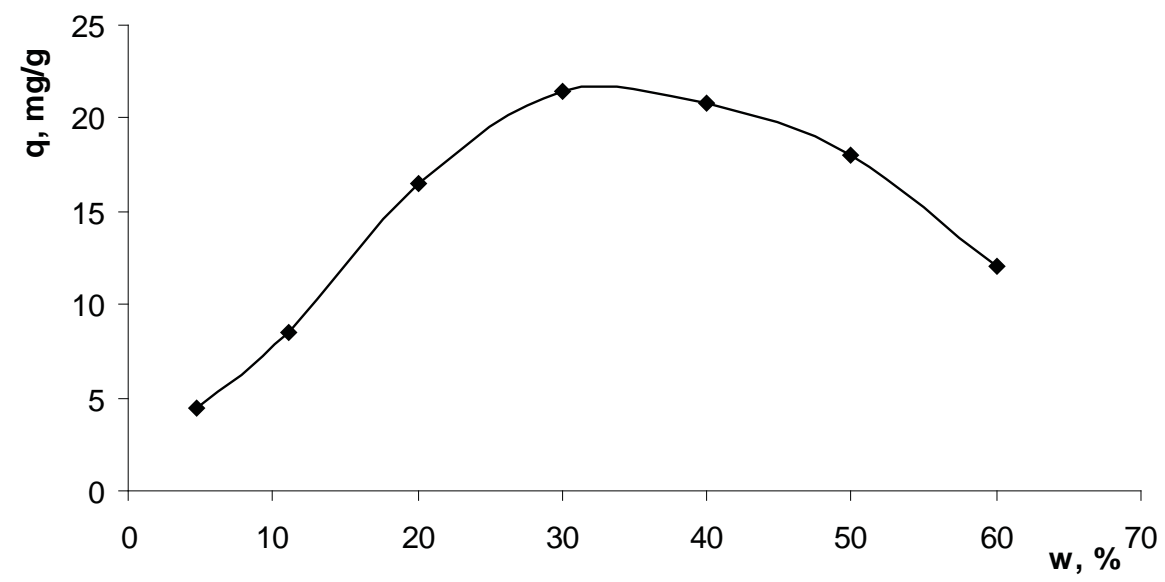

Fig. 3. The influence of the amine solution concentration used for impregnation on reactive sorption of tartaric acid by impregnated anionites

$\left(\mathrm{m}(\right.$ anionite $\left.)=0.5 \mathrm{~g} ; \mathrm{d}_{\mathrm{p}}=0.75 \mathrm{~mm} ; \mathrm{V}(\mathrm{AT})=50 \mathrm{~cm}^{3} ; \mathrm{c}_{\mathrm{o}}(\mathrm{AT})=0.8 \mathrm{~g} / \mathrm{dm}^{3} ; \tau_{\text {agit }}=60 \mathrm{~min} ; \mathrm{t}=28^{\circ} \mathrm{C} ; \mathrm{n}=150 \mathrm{~min}^{-1}\right)$

The increase of the amine solution concentration used for impregnation influenced positively anionite reactive sorption up to the concentration $30 \%$, and then decreased it. The explication is that the quantity of the fixed amine closes the access of the aqueous solution of tartaric acid to the resin pores.

The quantity of the solvent necessary for preparation of the amine solution also influenced the efficiency of the impregnation process and, further, of the tartaric acid separation. It was taken into account that the ration between amine content and resin weight must be constant, varying only solvent's volume. The organic solution with following volume ratio between Amberlite LA-2 and hexane were prepared: 1:1, 1:2, 1:3, 1:4 and 1:5. They corresponded to the amine solutions with concentration $56.23 \% ; 39.11 \% ; 29.99 \% ; 24.31 \%$ and $20.44 \%$, respectively. The quantities of the solutions used for impregnation were different $(0.754 \mathrm{~g} ; 1.084 \mathrm{~g} ; 1.414 \mathrm{~g} ; 1.744 \mathrm{~g}$ and $2.074 \mathrm{~g})$. 


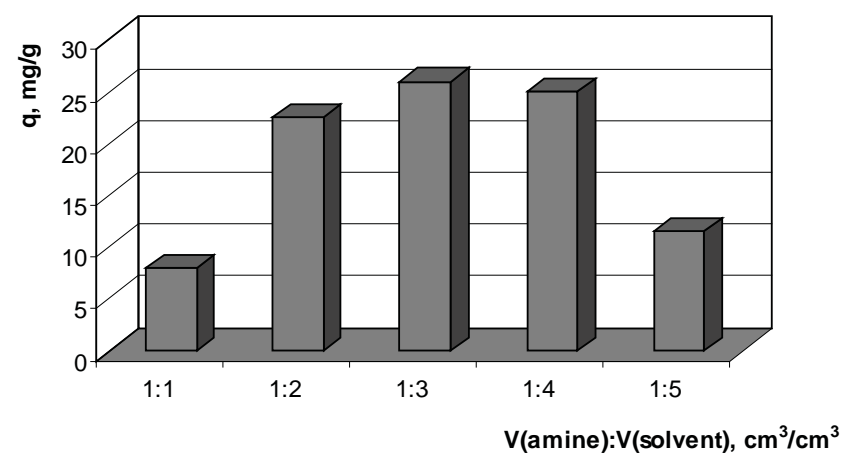

Fig. 4. The effect of the volume ratio between Amberlite LA-2 and hexane in impregnation solution on reactive sorption of the tartaric acid $\left(\mathrm{m}(\right.$ anionite $\left.)=0.5 \mathrm{~g} ; \mathrm{d}_{\mathrm{p}}=0.75 \mathrm{~mm} ; \mathrm{V}(\mathrm{AT})=50 \mathrm{~cm}^{3} ; \mathrm{c}_{\mathrm{o}}(\mathrm{AT})=0.95 \mathrm{~g} / \mathrm{dm}^{3} ; \tau_{\text {agit }}=15 \mathrm{~min} ; \mathrm{t}=27^{\circ} \mathrm{C} ; \mathrm{n}=150 \mathrm{~min}^{-1}\right)$

From the analysis of the figure 4 it is observed that the most adequate volume ratio between the amine and the solvent in impregnation solution was 1:3, corresponding to the solution of Amberlite LA-2 with concentration $30 \%$. This fact confirms once more experimental data received during determination of the impregnation solution concentration.

Amberlite XAD2 was impregnated with 30\% solution of Amberlite LA-2 for 1, 2, 4, 6, 8, 14, 16, 20 and $24 \mathrm{~h}$. It was shown that for the finalization of the impregnation was necessary $2 \mathrm{~h}$. The extension of procedure up to $12 \mathrm{~h}$ did not modify properties of the obtained anionite. Impregnation over $16 \mathrm{~h}$ led to insignificant decrease of obtained ion exchangers sorption, that can be explained by accumulation of the amine excess in resin pores (fig. 5). The anionite resulted after $24 \mathrm{~h}$ of Amberlite XAD2 impregnation did not differ by their properties from that obtained after 4 days of impregnation.

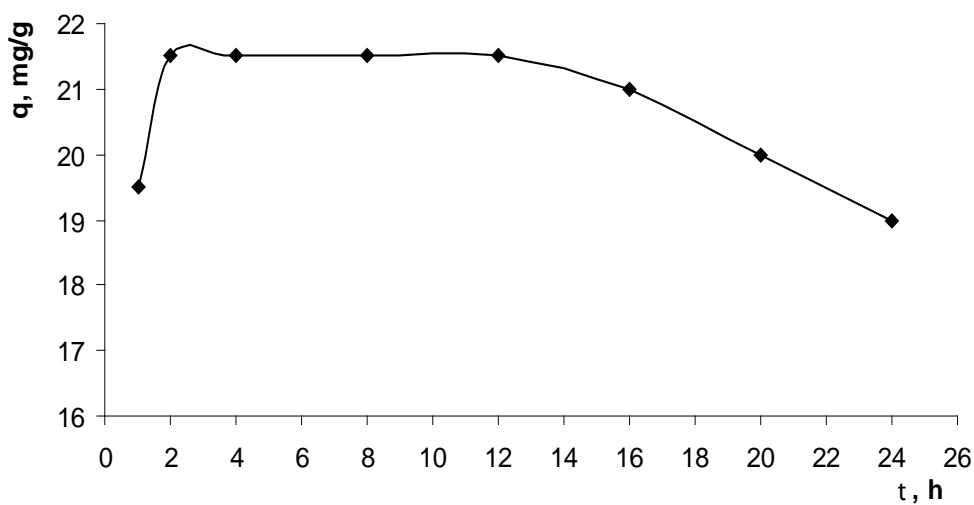

Fig. 5. The influence of the time of impregnation process on tartaric acid sorption on impregnated anionite $\left(\mathrm{m}(\right.$ anionite $\left.)=0.5 \mathrm{~g} ; \mathrm{d}_{\mathrm{p}}=0.75 \mathrm{~mm} ; \mathrm{V}(\mathrm{AT})=50 \mathrm{~cm}^{3} ; \mathrm{c}_{\mathrm{o}}(\mathrm{AT})=0.92 \mathrm{~g} / \mathrm{dm}^{3} ; \tau_{\text {agit }}=60 \mathrm{~min} ; \mathrm{t}=28^{\circ} \mathrm{C} ; \mathrm{n}=150 \mathrm{~min}^{-1}\right)$

Then, Freundlich and Langmuir isotherms for obtained anionite were verified. Isotherms of the reactive sorption of tartaric acid on Amberlite XAD2 impregnated with Amberlite LA-2 are present in figure 6.

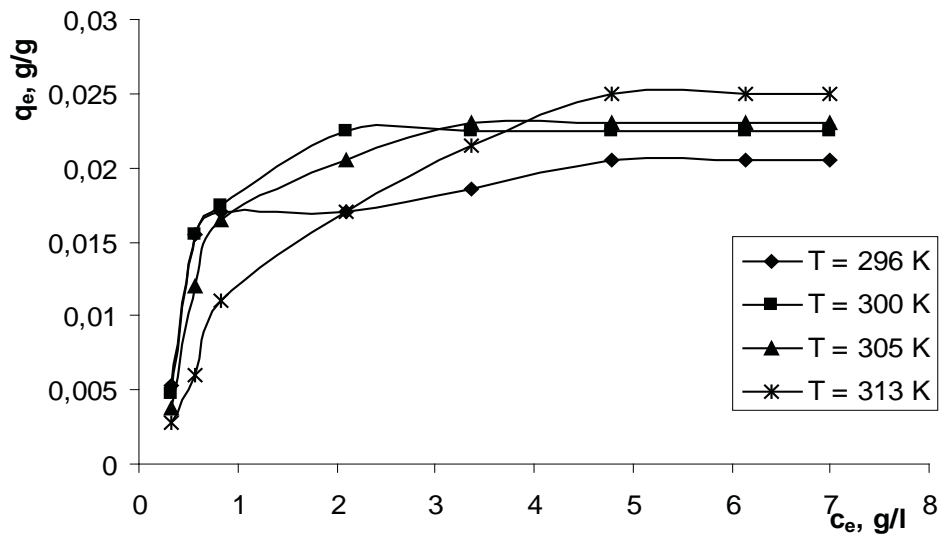

Fig. 6. Isotherms of reactive sorption of tartaric acid on Amberlite XAD2 impregnated with Amberlite LA-2 
Experimental data were processed according to Freundlich and Langmuir equations, and the results were presented in table 1. In figures 7 and 9 was illustrated experimental validation of the Freundlich and Langmuir equations for the reactive sorption of tartaric acid on Amberlite XAD2 impregnated with Amberlite LA-2 at $296 \mathrm{~K}$. In the same way were analyzed all isotherms.

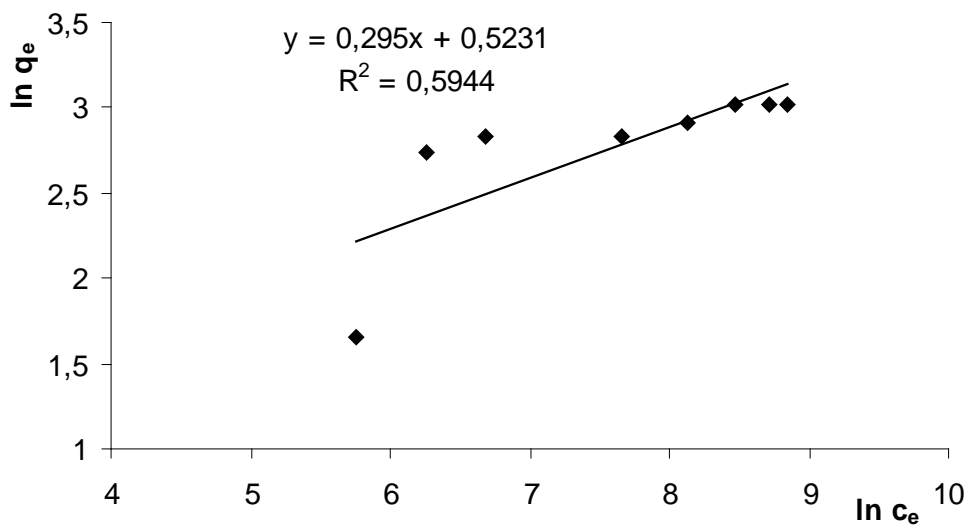

Fig. 7. Experimental validation of the Freundlich equation for the reactive sorption of the tartaric acid on Amberlite XAD2 impregnated with Amberlite LA-2 at $296 \mathrm{~K}$

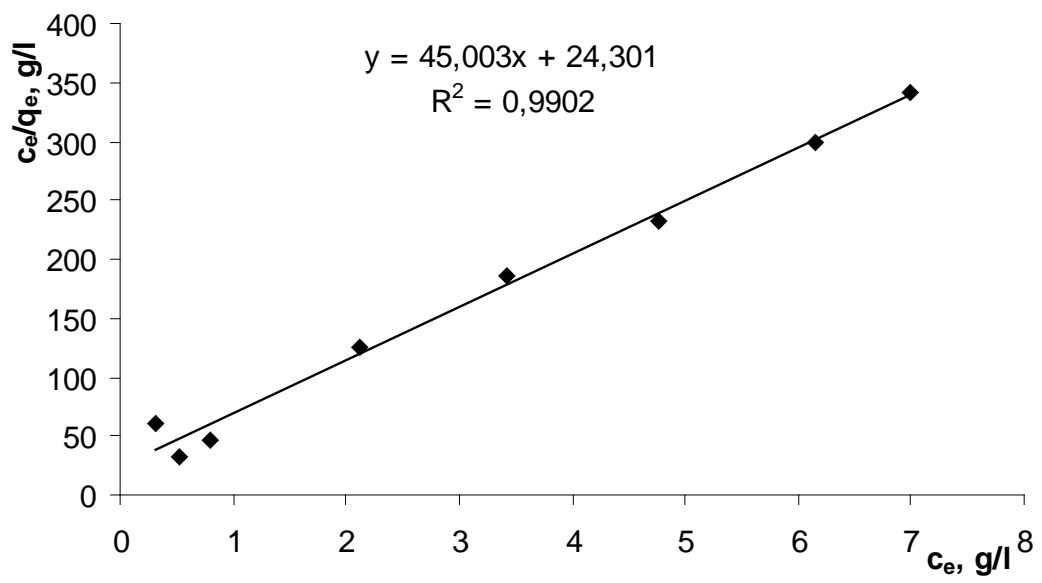

Fig. 8. Experimental validation of the Langmuir equation for the reactive sorption of the tartaric acid on Amberlite XAD2 impregnated with Amberlite LA-2 at $296 \mathrm{~K}$

\section{Constants of Freundlich and Langmuir isotherms}

\begin{tabular}{|c|c|c|c|c|c|c|}
\hline \multirow{2}{*}{$\mathrm{T}, \mathrm{K}$} & \multicolumn{3}{|c|}{ Freundlich } & \multicolumn{3}{c|}{ Langmuir } \\
\cline { 2 - 7 } & $\mathrm{n}$ & $\mathrm{K}_{\mathrm{F}}$ & $\mathrm{R}^{2}$ & $\mathrm{~K}_{\mathrm{L}}, \mathrm{L} / \mathrm{g}$ & $\mathrm{q}_{\mathrm{m}}, \mathrm{g} / \mathrm{g}$ & $\mathrm{R}^{2}$ \\
\hline 296 & 3,3898 & 1,6872 & 0,5944 & 1,8536 & 0,0222 & 0,9902 \\
\hline 300 & 2,7809 & 1,1264 & 0,6207 & 1,8079 & 0,0248 & 0,9807 \\
\hline 305 & 2,1925 & 0,5044 & 0,7096 & 1,0484 & 0,0270 & 0,9637 \\
\hline 313 & 1,4575 & 0,0727 & 0,9143 & 0,3253 & 0,0383 & 0,9259 \\
\hline
\end{tabular}

Comparison of the values of the correlation coefficients demonstrated that Langmuir equation verify experimental data in a better way. The values of the maximal specific reactive sorption, calculated with the same equation, increased at the same time with the temperature, which meant the interaction between tartaric ions and impregnated resin was an endothermic process.

Langmuir isotherm is mostly adequate for adsorption on energetic homogeneous surfaces, accompanied with the reaction [19-23]. Due to the established hypotheses, it allowed, after verification, determination of thermodynamic values $\Delta G^{o}, \Delta H^{o}, \Delta S^{o}$ (table 2). 
Table 2

Calculated thermodynamic constants

\begin{tabular}{|c|c|c|c|}
\hline $\mathrm{T}, \mathrm{K}$ & $\Delta \mathrm{G}^{\mathrm{o}}, \mathrm{J} / \mathrm{mol}$ & $\Delta \mathrm{H}^{\mathrm{o}}, \mathrm{J} / \mathrm{mol}$ & $\Delta \mathrm{S}^{\mathrm{o}}, \mathrm{J} /(\mathrm{mol} \cdot \mathrm{K})$ \\
\hline 296 & $-1518,83$ & \multirow{3}{*}{$-78850,18$} & $-261,26$ \\
\hline 300 & $-1477,09$ & & $-257,91$ \\
\hline 305 & $-119,86$ & & $-258,13$ \\
\hline 313 & 2922,59 & & $-261,25$ \\
\hline
\end{tabular}

Graphic dependency between the constant of equilibrium and the temperature allows estimating enthalpy and entropy of the tartaric acid separation process on Amberlite XAD2 impregnated with Amberlite LA-2.

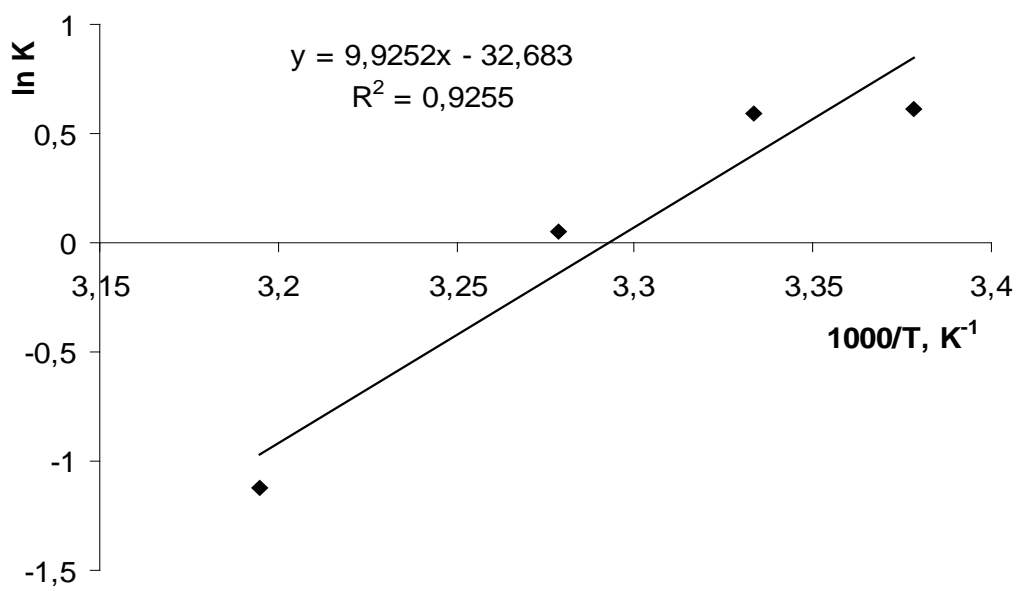

Fig. 9. The dependency of the natural logarithm of equilibrium constant $(\ln \mathrm{K})$ of the tartaric acid reactive sorption process on Amberlite XAD2 resin impregnated with Amberlite LA-2 on temperature $(1000 / T)$

Enthalpy value determined by graphic method was $-82524.07 \mathrm{~J} / \mathrm{mol}$, while entropy value $-271.75 \mathrm{~J} /(\mathrm{mol} \cdot \mathrm{K})$. Differences between the calculated and graphically determined results were $4.45 \%$.

$\Delta G^{o}$ represents modification of the free energy in standard state during the ion-exchange and sorption or desorption of the solvent and dissolved electrolyte [26, 27]. Negative value of Gibbs free energy modification denote spontaneous process of ion-exchange. But, increase of $\Delta G^{o}$ along with temperature shows its negative effect on the stability of the bonds between tartaric acid and ion-exchanger, which was confirmed by the decrease of equilibrium constant. Negative value of the enthalpy variation indicates an exothermic process, which is an additional argument. The selectivity of the sorption process characterized by negative value of the thermodynamic potential, is determined by the significant decrease of the entropy. This process represents the increasing of the energy of interaction between selectively fixed ions on the ionite, in comparison to the interaction energy of ionite with concurrent substituted ions, thus the complex between tartaric acid ion and anionite became more ordered.

System enthalpy variation in case of ion-exchange for diluted solutions was caused by the variation of the energy of interactions between contra-ions and ionite. Generally, bond energy between the ions of organic substances and ionexchangers is lower than between simple monovalent ions of hydrogen, chloride or metal ions (the influence of ion radius). Thus, the values of the thermodynamic potential, enthalpy and entropy support the existence of supplementary interactions, e.g., van der Waals bonds or hydrophobic interactions [27].

\section{Conclusions}

The investigation revealed that for the impregnation of macroporous resin Amberlite XAD2 should be used Amberlite LA-2 amine, in following conditions: solvent - hexane, ratio between amine volume and solvent volume was $1: 3$, the concentration of amine solution in hexane $30 \%$ and impregnation time at least $2 \mathrm{~h}$.

Tartaric acid reactive sorption process on the obtained impregnated anionite verifies Langmuir equation with correlation higher than 0.92 , and thermodynamic constants denotes the presence of exothermal process, associated with chemical reaction.

\section{References}

[1]. Warshawsky, A. South African Patent Application 71/5637, 1971.

[2]. Tavlarides, L. L.; Bae, J. H.; Lee, C. K. Solvent extraction, membranes, and ion-exchange in hydrometallurgical dilute metals separation. Separation Science and Technology. 1987, 22(2-3); pp. 581-617. 
[3]. Juang, R.-S.; Chou, T.-C. Sorption of citric acid from aqueous solutions by macroporous resins containing a tertiary amine - Equilibria. Separation Science and Technology, 1996, 31(10), pp. 1409-1425.

[4]. Traving, M.; Bart, H.-J. Recovery of organic acids using ion-exchanger impregnated resins. Chemical Engineering Technology, 2002, 25(10), pp. 997-1003.

[5]. Babić, K.; van der Ham, L. G. J.; de Haan, A. B. Sorption kinetics for the removal of aldehydes from aqueous streams with extractant impregnated resins. Adsorption, 2008, 14, pp. 357-366.

[6]. Cortina, J.; Miralles, N.; Sastre, A.; Aguilar, M.; Profumo, A.; Pesavento M. Solvent impregnated resins containing di(2,44-trimethylpentyl)phosphinic acid. I. Comparative study of di(2,44-trimethylpentyl)phosphinic acid adsorbed on Amberlite XAD-2 and dissolved in toluene. Reactive Polymers, 21, 1993, pp. 89-101.

[7]. Cortina, J.; Miralles, N.; Sastre, A.; Aguilar, M.; Profumo, A.; Pesavento M. Solvent impregnated resins containing di(2,44-trimethylpentyl)phosphinic acid. II. Study of the distribution equilibria of $\mathrm{Zn}, \mathrm{Cu}$ and $\mathrm{Cd}$. Reactive Polymers, 21, 1993, pp. 103-116.

[8]. Warshawsky, A. Extraction with Solvent-Impregnated Resins. V. 8 of Ion Exchange and Solvent Extraction. Marcel-Dekker: New York, 1981, pp. 229-310.

[9]. Cortina, J.; Meinhardt, E.; Roijals, O.; Marti, V. Modification and preparation of polymeric adsorbents for precious-metal extraction in hydrometallurgical processes. Reactive and Functional Polymers, 1998, 32(2), pp. 149-165.

[10]. El-Dessouky, S.; Borai, E. Extraction chromatography of thorium ion by solid phase impregnated resins containing bi-functional organic extractants. Journal of Radioanalitycal and Nuclear Chemistry, 2006, 268(2), pp. 247-254.

[11]. Babić, K.; van der Ham, L. G. J.; de Haan, A. B. Recovery of benzaldehyde from aqueous streams using extractant impregnated resins. Reactive and Functional Polymers, 2006, 66(12), pp. 1494-1505.

[12]. Cabasso I., Jagur-Grodzinski, J.; Vofsi, D. Polymeric alloys of polyphosphonates and acetyl cellulose. I. Sorption and diffusion of benzene and cyclohexane. Journal of Applied Polymer Science, 1974, 18, pp. 2117-2136.

[13]. van den Berg, C. In-situ product recovery from fermentation broths. The application of solvent-impregnated resins as a product recovery tool. Printpartners Ipskamp B.V., 2010, $121 \mathrm{p}$.

[14]. Ruiz, M.O.; Cabezas, J.L.; Escudero, I.; Alvarez, J. R.; Coca, J. $\alpha$-Phenylglycine extraction with a trialkylmethylammonium chloride-impregnated macroporous resin. 1. Equilibrium. Trans IChemE, 2002, 40(A), pp. 529-536.

[15]. Juang, R.-S.; Chang, H.-L. Distribution equilibrium of citric acid between aqueous solutions and tri-n-octylamineimpregnated macroporous resins. Industrial and Engineering Chemistry Research, 1995, 34, pp. 1294-1301.

[16]. Ruiz, M. O.; Cabezas, J. L.; Escudero, I.; Alvarez, J. R.; Coca, J. Valeric acid extraction with tri-N-butyl phosphate impregnated in a macroporous resin. I. Equilibrium and mass transfer rates. Separation Science and Technology, 2004, 39(1), pp. 77-95.

[17]. Kostova, A.; Bart, H.-J. Equilibrium study of amino acid reactive sorption with solvent impregnated resins, Part I. Solvent Extraction and Ion Exchange, 2007, 25, pp. 109-126.

[18]. Razuvaev, N.I. Complexnaya pererabotka vtoricnih productov vinodelia. Moscow, 1975.

[19]. Aksu, Z. Equilibrium and kinetic modeling of cadmium(II) biosorption by C. vulgaris in a batch system: effect of temperature. Separation and Purification Technology, 2001, vol. 21, pp. 285-294.

[20]. Benguella, B.; Benaissa, H. Cadmium removal from aqueous solution by chitin: kinetic and equilibrium studies. Water Research, 2002, vol. 36, no. 10, pp. 2463-2474.

[21]. Moazed, H. Ammonium ion removal from wastewater by a natural resin. Journal of Environmental Science and Technology, 2008, 1(1), pp. 11-18.

[22]. Visa, M. Heavy metals removal on due - modified fly ash substrates. World of Coal Ash Conference - May 9-12, 2011, Denver, CO, USA, http://www.flyash.info/

[23]. Sun, X.; Li, C.; Wu, Z.; Xu, X.; Ren, L.; Zhao, H. Adsorption of protein from model wine solution by different bentonites. Chin. J. Chem. Eng., 2007, 15(5), pp. 632-638.

[24]. Koolman, J.; Röhm, K.-H. Color atlas of biochemistry. (translation in Russian) Mir, Moscow, 2000, 469 p. http:// www.chem.msu.su/rus/teaching/kolman/26.htm 13.11.2011.

[25]. Kannan, N.; Veemaraj, T. Detoxification of toxic metal ions by sorption onto activated carbon from Hevea Brasiliensis bark - a comparative study. Global NEST Journal, Vol. 12, No 2, 2010, pp. 197-205.

[26]. Grissbach, R. Theory and practice of ion-exchange. Publishing house Inostrannaia literatura, 1963, Moscow, $499 \mathrm{p}$.

[27]. Samsonov, G. V.; Trostianscaia, E. B., Elkin, G. E. Ion-exchange. Organic substances sorption. Publishing house Nauca, Lenigrad, 1969, 336 p. 